\title{
$\mathrm{Nd} \cdot \mathrm{Fe}-\mathrm{B}$ 磁石，その着想と実際*
}

佐川眞

\section{Masato Sagawa: Nd-Fe-B Magnet, Its Idea and Reality.}

The research of the Nd-Fe-B magnet was started from an expectation that $\mathrm{B}$ and/or $\mathrm{C}$ might expand $\mathrm{Fe}-\mathrm{Fe}$ interatomic distances in rare-earth iron alloys, leading to increase the Curie temperature of them. After the success in developing the powerful Nd-Fe-B sintered magnets with record high energy products, however, a crystal structure analysis revealed that $\mathrm{Fe}-\mathrm{Fe}$ pairs having small interatomic distances existed also in the Nd-Fe-B alloy. It is emphasized that the success in this work is a result of many fortunate matters which were not expected in the beginning.

(Received June 29, 1987)

$\mathrm{R}_{2} \mathrm{Fe}_{17}$ (R は希土類元素) のキュリー温度 $\mathrm{Tc}$ が $\alpha-\mathrm{Fe}$ や RCo 化合物比比へて極端に低いのは， $\mathrm{R}_{2} \mathrm{Fe}_{17}$ 中の dumbbell と呼ばれる， 2 個対になった $\mathrm{Fe}$ 原子の間の 距離が, $0.24 \mathrm{~nm}$ 以下で大変小さいととに原因がある. ある講演会でこの話を聞いたとき，筆者は $\mathrm{RFe}$ 化合物 に C や B など原子半径の小さい元素を添加すれば, $\mathrm{Fe}-\mathrm{Fe}$ 原子間距離が拡がり, Tc が上がるのではないか と考えた. Nd-Fe-B 磁石の研究はこの時から始まった。

数年後, 我々は1 $12 \mathrm{at} \% \mathrm{Nd}, 6 \mathrm{at} \% \mathrm{~B}$, 残り $\mathrm{Fe}$ 付近 の組成に, $a=0.88 \mathrm{~nm}, c=1.22 \mathrm{~nm}$ の正方晶構造を持 ち，永久磁石材料として優れた性質を示す安定な化合物 が存在するととを見出した。 この化合物をむとにして， 記録的な磁気エネルギー積を持つ強力な磁石を開発した。

我々の発表後, この相の詳細な構造は, Herbst ら2) により中性子回折に上って, Givord らろにより, X 線 回折によって, 独立に解明され，その化学量諭比が $\mathrm{R}_{2} \mathrm{Fe}_{14} \mathrm{~B}$ であること, $\mathrm{P}_{2} / \mathrm{mnm}$ という対称性を持ち,

Fig. 1 亿示されるような構造を持っているてとが初めて 明らかにされた。この構造はつぎの特徵を持っている。

(1)全ての $\mathbf{R}$ と $\mathrm{B}$ は， $z=0$ と $z=1 / 2$ の層に集中して いる.

(2) $\mathrm{Fe}$ の大部分 (96\%) は $\mathrm{R}$ と B を含む層の間にあり,

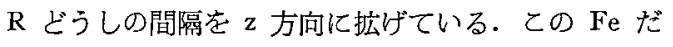
けの層は，Fe-Cr 合金などに見られる $\sigma$ 相とよく似た 構造を有している.

$\mathrm{R}_{2} \mathrm{Fe}_{14} \mathrm{~B}$ の構造は我々の予想通りではなかった。我々 は $\mathrm{R}_{2} \mathrm{Fe}_{14} \mathrm{~B}$ 中には， $\mathrm{R}_{2} \mathrm{Fe}_{17}$ 中におりる dumbbell $\mathrm{Fe}$ ペアーの上うな，短い原子間距離を持つペアーは存在し ないであろうと予想していた. ところが実際には Fig.1 で, $8 \mathrm{j}_{1}$ と $16 \mathrm{k}_{2}$ の間の原子間距離は $0.2396 \mathrm{~nm}, 8 \mathrm{j}_{1}$ 之, 隣りの $8 j_{1}$ の間の距離は $0.2433 \mathrm{~nm}$ で, 事情は $\mathrm{R}_{2} \mathrm{Fe}_{17}$ の場合とあまり変わらないことが判明した. Cゃ $\mathrm{B}$ が R-Fe 化合物の原子間距離を拡げ，Tcを上げるか も知れないという着想は $\mathrm{R}_{2} \mathrm{Fe}_{14} \mathrm{~B}$ にあてはまらない。
$\mathrm{Nd}-\mathrm{Fe}-\mathrm{B}$ 磁石の発見は全くのまぐれ当たりであった。 まぐれ当たりはそれだけではない，Nd-Fe-B 磁石の 記録的な高性能はいくつもの幸運が重なった結果である. そのひとつは $\mathrm{R}_{2} \mathrm{Fe}_{14} \mathrm{~B}$ の磁気異方性についてである.

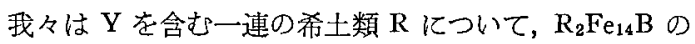
単結晶を作製して, 磁気的性質を測定した ${ }^{4,5)}$. その結果, $\mathrm{R}_{2} \mathrm{Fe}_{14} \mathrm{~B}$ の1次の磁気異方性定数 $\mathrm{Ku}_{1}$ \& $\mathrm{R}=\mathrm{Nd}, \mathrm{Pr}$, Tb, Dy, Ho に対して正 (結晶の $\mathrm{c}$ 軸方向力磁化容易方 向, 高保磁力を得るための必要条件), $\mathrm{R}=\mathrm{Sm}, \mathrm{Er}, \mathrm{Tm}$ に対して負（c面内に磁化容易方向が哲り，高保磁力は 得られない)であることが判明した．との事情は，てれ までに知られている R・T ( T は Fe または Co) 2 元化 合物と全く逆である. これは $\mathrm{R}_{2} \mathrm{Fe}_{14} \mathrm{~B}$ の構造的特徽に 原因がある.すなわち， $\mathrm{R}_{2} \mathrm{Fe}_{14} \mathrm{~B}$ では $\sigma$ 相似似た $\mathrm{Fe}$ だけの層によって， R イオンどうしが $\mathrm{c}$ 軸方向に大きく 隔てられている.4f 電子の空間分布が全角運動量 $\mathrm{J}$ に 対して偏平に昖がっている $\mathrm{R}=\mathrm{Nd}$ のグループは，電子 雲が $\mathrm{c}$ 面内搪がったよう化分布する方が静電エネルギ 一が低いので，Jは $\mathrm{c}$ 軸方向を向く. 葉巻型の電荷分布 を持つ $\mathrm{R}=\mathrm{Sm}$ のグループはその逆である.これまでの 2 元化合物は，いずれむ $\mathrm{R}$ イオンどうしの原子間距離 は $\mathrm{c}$ 軸方向の方が $\mathrm{c}$ 面内より小さいので, $\mathrm{R}=\mathrm{Nd}$ の グループは $\mathrm{c}$ 面内に磁化容易方向を持つ. C p B を添 加するという最初の着想のとき, 磁気異方性については 何も考慮しなかった. $\mathrm{R}_{2} \mathrm{Fe}_{14} \mathrm{~B}$ において， $\mathrm{R}=\mathrm{Nd}$ のグ ループが正の磁気異方性を持つととは全くのまぐ礼当た りであった。

第 3 の幸運は Nd-Fe-B 系の状態図に関係している.

Fig. 2 Kd-Fe-B 3 元系の液相に関する状態図を示 す6). ここで $\mathrm{T}_{1}$ は $\mathrm{Nd}_{2} \mathrm{Fe}_{14} \mathrm{~B}, \mathrm{~T}_{2}$ は $\mathrm{Nd}_{1.1} \mathrm{Fe}_{4} \mathrm{~B}_{4}$, そし て $\mathrm{T}_{3}$ は $\mathrm{Nd}_{2} \mathrm{FeB}_{3}$ である. 高い保磁力は $\mathrm{T}_{1}, \mathrm{~T}_{2}$ 扔よ

* 第10回（昭和61年度）研究進步賞受賞，昭和62年 6 月本協 会春季大会にて発表, 昭和62年6月29日受理.

** 住友特殊金属(株)，广618 大阪府三舄郡島本町江川2-15-17. 


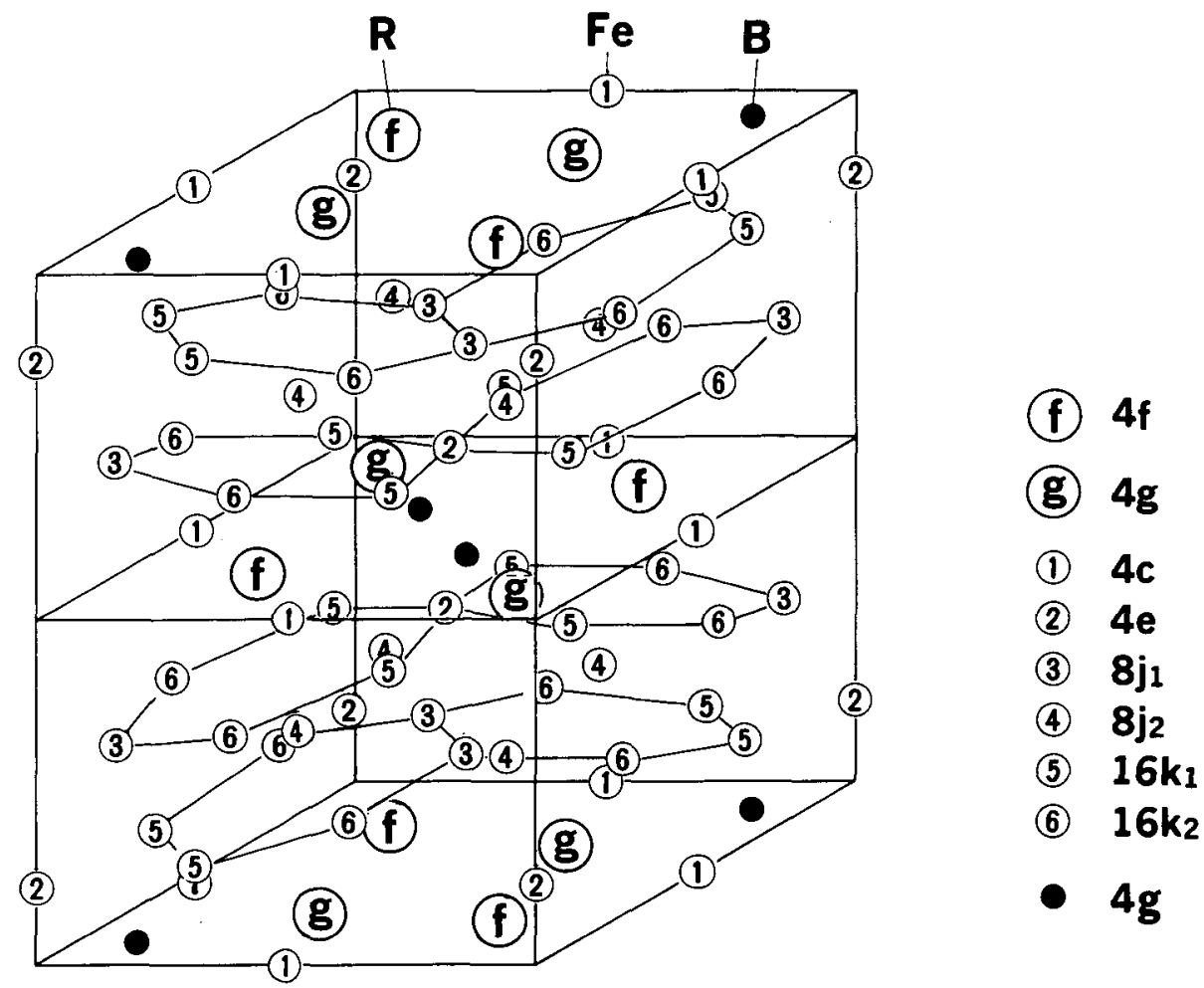

\section{$\mathrm{R}_{2} \mathrm{Fe}_{14 \mathrm{~B}}$}

Fig. 1 Crystal structure of $\mathrm{R}_{2} \mathrm{Fe}_{14} \mathrm{~B}$.

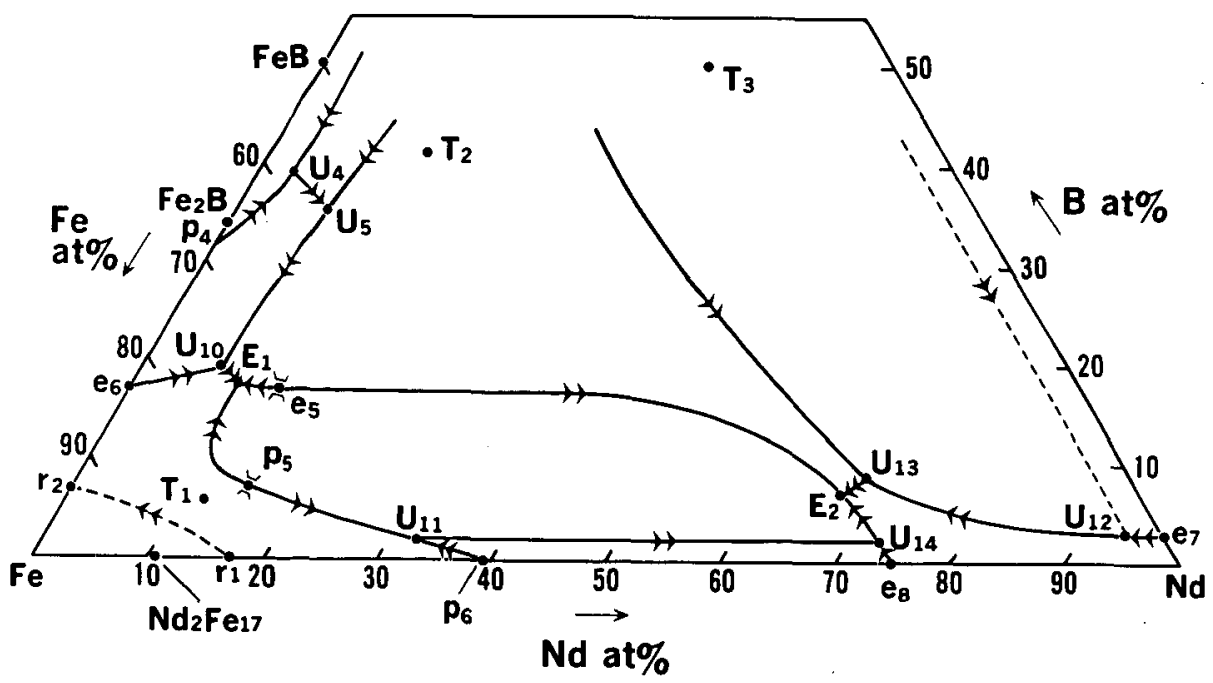

Fig. 2 Liquid phase projection of the Nd-Fe-B ternary system. $\mathrm{T}_{1} ; \mathrm{Nd}_{2} \mathrm{Fe}_{14} \mathrm{~B}, \mathrm{~T}_{2} ; \mathrm{Nd}_{1.1} \mathrm{Fe}_{4} \mathrm{~B}_{4}, \mathrm{~T}_{3} ; \mathrm{Nd}_{2} \mathrm{FeB}_{3}$

び Nd を囲む三角形の内側で得られる.とりわけ， $\mathrm{T}_{2}$ より, $\mathrm{Nd}$ と B が少し過剩な組成領域で高い $(\mathrm{BH})_{\max }$ が得られる. てのような合金は, 主相 $\mathrm{Nd}_{2} \mathrm{Fe}_{14} \mathrm{~B}$ と, 少 量の $\mathrm{T}_{2}$ 相拉よび $\mathrm{Nd}$ からなる.この合金の高保磁力は 少量の相， $\mathrm{T}_{2}$ と $\mathrm{Nd}$ がとすに非磁性であること，そし $\tau, T_{1}, T_{2}, N d$ が低温で 3 元共晶を持つととと深く関わ っている.

$\mathrm{Nd}-\mathrm{Fe}-\mathrm{B}$ 磁石はニュークリエージョン型磁石である. 一方向に磁界を印加して，焼結体を着磁すると，逆方向 に磁界が印加されても逆磁区の芽がなかなかできない． 
大きい逆磁界を印加して，いったん逆磁区の芽ができる 上，結晶粒内に磁壁をピン止めするすのがないので，い っぺんに磁化反転が起こる、ニュークリエーション,す なわち逆磁区の芽の発生は磁石中の磁気的に柔ら加い 点で起こる.同じニュークリエーション型磁石である $\mathrm{SmCo}$ 型磁石では, $\mathrm{Sm}_{2} \mathrm{Co}_{7} や \mathrm{Sm}_{2} \mathrm{Co}_{17}$ な゙の, $\mathrm{SmCo}_{5}$ より磁気的に柔らかい不純物相加らニュークリエーショ ンが起こると推定されている，ところが，Nd-Fe-B 系 では主相以外は非磁性なので，少量の相はニュークリエ ーションサイトにならない，したがって，組成が狙いよ り少しくらいずれてす Nd-Fe-B 系では高保磁力が得や すい.

$T_{1}, T_{2}, N d の 3$ 元結晶 $E_{2}$ 点の存在は液相焼結を可能 にし，結晶粓成長を起こさずに高密度化ができる，また 焼結中に生成する $\mathrm{Nd}$ に富んだ液相は，合金の粉砕中に できた Nd-poor な粉末表面を好らし，そこに Nd を供 給する. $\mathrm{E}_{2}$ 地点で生成した純 $\mathrm{Nd}$ 相（実際には3〜5 \%程度 $\mathrm{Fe}$ を含む）は $\mathrm{Nd}_{2} \mathrm{Fe}_{14} \mathrm{~B}$ の結晶粒を1つ1つ隔 離する働きをする.こうして,ニュークリエーション型 磁石として理想的な金属学的組織が形成される: Nd-FeB 系を調ベてみようと思ったとき，金属学的条件につい ては全く何あ考えなかった。

Nd-Fe-B 磁石において，幸運であったととは他にも たくさんある.とれらの幸運のどれ加1つであ欠けてい たら，Nd-Fe-B 磁石は日の目を見なかったであろう。

$\mathrm{Nd}-\mathrm{Fe}-\mathrm{B}$ 磁石の発明は，工業界はもよより，基礎研究 の分野にあ強いインパクトを与えた，ての意味で，てれ はまぐれ当たりであったけれよ゙，結果として独創的な研 究といって良いであるう．私は，乙の仕事を通じて，独 創的な研究がいかに多くの幸連の所産であるかを痛感し た，その幸運はめったにやっててない，それが何重にあ 重なることはさらに稀なことである。

近年, 日本人の独創性について議論されることが多く なった．雄誌や新聞で，先輩・諸先生方のご意見を拝読 して感銘を受けることがしばしばある。しかし，応用磁 気学会誌の最新号に発表された, 関澤先生 (千葉工大) ${ }^{7}$ のご意見には疑問を感じる.

先生はつぎのように述べておられる。

(1)ディラックやストラビンスキーのような独創力を獲得 したり養成したりすることに悲観的である。

(2)独創は多すぎては困る。

(3)サッチャー首相が “英国で創造された科学が, 日本で
実用化している”と言ったが，劣等感を抱く必要はな い. 大独創しかできない国と小独創を得意とする国の 間で国際的分業が成立するととが望ましい。

これに対して私はつぎのように考える。まず，ディラ ックやストラビンスキー（なぜとてに出てくるのか?） などの巨星だけが独創的というのなら悲感的にならざる を得ない. 私が疑問を感じるのは特に第 2 の点である. 独創的なるのが生まれる確率はきわめて少ないのだから， できるだけ多くの人が，成功すればインパクトの大きい 何かを狙って研究すべきである．少しでも大きい研究テ ーマにチャレンジするべきである．応用研究に限らず， 基礎研究においても，成功すればどれくらいのインパク トがあるかをテーマ選定の 1 つの規準とするべきである。 関澤先生ので意見の第 3 点は一種の開きなおりである. 貿易摩擦の問題でもそうであるが，もう開きなおりでは 済まなくなっている．科学技術摩擦を起てさないための 具体的な行動が必要である。

$\mathrm{Nd} \cdot \mathrm{Fe}-\mathrm{B}$ 磁石の生産量は大きく伸展しようとしてい る.現在最大の用途は磁氮ディスク装置のボイスコイル モーター (VCM) である.フロッピーディスクのヘッド 駆動用ステッピングモーター，小型ハードディスクのへ ッド駆動用トルクモーター，ワイヤドットプリンタ用へ ッド，ビデオディスクやコンパクトディスクのピックア ップ, $8 \mathrm{~mm}$ ビデオのレンズ駆動アクチュエーターやテ ープ駆動用小型モーターなど多数の用途が実用段階に入 っている. 磁気共鳴画像診断装置 (MRI=Magnetic Resonance Imaging) の磁気回路や自動車用電装部品も, 今後のコストダゥンしだいでは，Nd-Fe-B 磁石の大きい 市場になること加期待されている。

\section{文献}

1) M. Sagawa, S. Fujimura, N. Togawa, H. Yamamoto and Y. Matsuura: J. Appl. Phys., 55 (1984), 2083.

2) J. F. Herbst, J. J. Croat, F. E. Pinkerton and W. B. Yellon: Phys. Rev., B29 (1984), 4176.

3) D. Givord, H. S. Li and J. M. Moreau: Solid State Commun., 50 (1984), 497.

4) M. Sagawa, S. Fujimura, H. Yamamoto, Y. Matsuura and S. Hirosawa: J. Appl. Phys., 57 (1985), 4094.

5) S. Hirosawa, Y. Matsuura, H. Yamamoto, S. Fujimura and M. Sagawa: J. Appl. Phys., 59 (1986), 873.

6) Y. Matsuura, S. Hirosawa, H. Yamamoto, S. Fujimura, M. Sagawa and K. Osamura: Jpn. J. Appl. Phys., 24 (1985), L635.

7）関臎：日本応用磁気学会誌，3 (1987)，459. 